\title{
Hepatic, Gut, and Renal Substrate Flux Rates in Patients with Hepatic Cirrhosis
}

\author{
O. E. Owen, F. A. Reichle, M. A. Mozzoli, T. Kreulen, M. S. Patel, \\ I. B. Elfenbein, M. Golsorkhi, K. H. Y. Chang, N. S. RaO, H. S. Sue, and \\ G. Boden, Departments of Medicine, Surgery, Pathology, and Biochemistry, \\ General Clinical Research Center and Fels Research Institute, Temple University \\ Health Sciences Center, Philadelphia, Pennsylvania 19140
}

\begin{abstract}
A B S T RAC T The roles of liver, kidney, and gut in maintaining fuel homeostasis were studied in 28 patients with severe hepatic cirrhosis, 25 of whom had alcohol-induced cirrhosis. Hepatic, portal, and renal blood flow rates were measured and combined with substrate concentration differences across liver, gut, and kidney to calculate the net flux of free fatty acids, ketone bodies, triglycerides, and glucose with selected glucose precursors, including glycerol, lactate, pyruvate, and amino acids. Data from the catheterization studies were related to hepatic histology, glycogen content, and activities of gluconeogenic enzymes and compared with data obtained from control patients. The effects of food deprivation on net flux of fuels across the liver, gut, and kidney were assessed after overnight and after $3 \mathrm{~d}$ of fasting.
\end{abstract}

Activities of gluconeogenic enzymes were normal, but hepatic glycogen content was diminished in cirrhotic livers, probably as a consequence of extensive hepatic fibrosis. Extrahepatic splanchnic tissues (gut) had only a small influence on total splanchnic flux rates of carbohydrates, lipids and, amino acids. In cirrhotic patients, there was no mean renal glucose contribution to the bloodstream after an overnight or after a 3-d fast.

After an overnight fast hepatic glucose production in patients with cirrhosis was diminished as a result of low-rate glycogenolysis. Hepatic gluconeogenesis and ketogenesis were increased. This pattern of hepatic metabolism mimics that seen in "normal" patients after more advanced stages of starvation. After $3 \mathrm{~d}$ of starvation, patients with hepatic cirrhosis have hepatic

F. A. Reichle is presently chairman of surgery, PresbyterianUniversity of Pennsylvania Medical Center, Philadelphia, Pa. 19104. Address reprint requests to Dr. O. E. Owen, Temple University Hospital.

Received for publication 15 September 1980 and in revised form 25 February 1981. gluconeogenic and ketogenic profiles comparable to those of normal patients undergoing starvation of similar duration. Nevertheless, the total number of caloric equivalents derived from ketone bodies plus glucose corrected for recycled lactate and pyruvate added to the bloodstream by the cirrhotic livers that could be terminally oxidized by peripheral tissues was less than the contributions made by the normal livers, both after an overnight and after a 3-d fast.

\section{INTRODUCTION}

The enormity of the cost associated with hepatic cirrhosis, especially alcoholic cirrhosis, in the United States is recognized (1). In urban states cirrhosis has become the third cause of death in active individuals between 25 and 65 years of age (2). However, there have been relatively few studies published on the effects of hepatic cirrhosis, particularly those of ethanolinduced Laennec's cirrhosis, on individual organ systems and on the consequences of these alterations for the maintenance of fuel homeostasis $(3,4)$. To delineate the roles of individual organs in maintaining fuel homeostasis in patients suffering from hepatic cirrhosis, we carried out hemodynamic and metabolic measurements in unanesthetized patients with cirrhosis and portal hypertension. Cardiac, hepatic, portal, and renal blood flow rates were measured and combined with substrate concentration differences across liver, gut, and kidney to calculate net flux rates of glucose and selected glucose precursors, including amino acids and selected lipids. Limited studies were also performed in "normal" patients. The results from the catheterization studies were integrated with hepatic histology, glycogen content, and gluconeogenic enzymes. To assess the effects of food deprivation, catheterization studies were carried out after an overnight or a 3-d fast. The data from our cirrhotic patients were compared with the data obtained from 
our normal patients combined with the results obtained by Wahren et al. (5) from normal volunteers.

\section{METHODS}

\section{Patients}

Five groups of patients were studied. Groups I and II had hepatic cirrhosis and are described in detail. Groups III-V were studied to obtain normal control data. Due to the complexity of these investigations, not all studies were performed on each patient.

All patients were informed of the nature, purpose, and possible risks and benefits of the studies before giving their voluntary, written consent. The study protocol was approved by the Research Review Committee of Temple University Hospital.

Groups I and II. 28 patients with liver disease were studied. They entered the hospital with massive gastroesophageal variceal hemorrhages, secondary to hepatic cirrhosis and portal hypertension. After blood transfusion, hemostasis, and parenteral nutrition with multiple vitamin supplementation, they were transferred to the General Clinical Research Center at Temple University Hospital.

After stabilization, they were given diets designed to be anabolic and containing at least $1 \mathrm{~g}$ protein $/ \mathrm{kg}$ body wt in addition to carbohydrates, fats, minerals, and vitamins, with more than $22 \mathrm{kcal} / \mathrm{kg}$ body wt. Those patients unable to consume at least this quantity of nourishment orally received supplementary parenteral glucose and amino acids (Aminogen, Baxter Laboratories, Morton Grove, Ill., or Freamine, McGraw Laboratories, Irvine, Calif.). Thereafter, they were divided into two groups, determined by how long they fasted before undergoing investigational catheterization studies. Group I was catheterized after an overnight fast (8$10 \mathrm{~h}$ ), and group II was catheterized after a 3-d fast (80-82 h).

There were 16 male and 12 female patients in groups I and II. The mean age of the overnight and 3-d fasted groups was $50 \mathrm{yr}$, with a range of 30 to $75 \mathrm{yr}$. Body surface area was calculated from height and weight, irrespective of the presence or absence of edema or ascites. Although the heights and weights, and thus the dependent body surface areas, were normal, the majority of the patients had clinical evidence of diminished muscle mass. 11 patients had ascites. One patient had insulin-dependent diabetes mellitus in addition to Laennec's cirrhosis. Two patients may not have consumed and one patient did not consume the quantities of alcohol generally considered necessary to induce cirrhosis (6).

The laboratory data obtained from analyzing peripheral venous serum or plasma after good nutrition for days to weeks, and just before liver biopsies were performed, showed that the total protein concentrations in both groups were normal. However, the mean albumin concentrations were decreased $(<3.5 \mathrm{~g} / \mathrm{dl})$ in 18 of 28 cirrhotic patients. Total bilirubin was increased $(>1.2 \mathrm{mg} / \mathrm{dl})$ in 22 patients, and alkaline phosphatase activity was $>100 \mathrm{IU} /$ liter in 18 patients. The serum transaminase activity was increased ( $>40$ IU/liter) in 23 patients. No patient had evidence of antecedent renal disease, and, in contrast to the commonly observed abnormal liver functions, all patients had a normal urinalysis and all but one had normal creatinine concentrations. Two patients had elevated serum urea nitrogen concentrations of 31 and $37 \mathrm{mg} /$ $\mathrm{dl}$, respectively. The insulin-dependent diabetic patient received his last injection of insulin $24 \mathrm{~h}$ before the catheterization study. Since the results from the study of this patient were comparable to those from other cirrhotic patients, they were included in the data.
At the time of the catheterization study, none of the patients had evidence of acute medical illness, and no patient had a hematocrit of $<30 \%$; therefore, anemia severe enough to cause alterations in cardiac output or regional blood flow (7) was not present.

Group III. 13 patient volunteers requiring diagnostic cardiac catheterization were studied after an overnight (9$12 \mathrm{~h}$ ) fast. They were selected after clinical assessment and were thought to have minimal cardiovascular abnormalities but required coronary angiography. After diagnostic studies some were found to be normal and the others had no significant hemodynamic alterations. Before the diagnostic component of the study, their brachial arteries and right main hepatic veins were catheterized to determine net splanchnic acetoacetate $(\mathrm{AcAc})^{1}$ and $\beta$-hydroxybutyrate $(\beta$-OHB) production rates after an overnight fast. Net splanchnic glucose production rates and gluconeogenic precursor extraction rates have been published by Wahren et al. (5). The experimental conditions were similar to those emploved in the overnight fasted cirrhotic patients (see below). Additional arterial blood was drawn to determine the normal circulating concentrations of lactate, pyruvate, glycerol, alanine, glutamine, glutamate, glucose, FFA, immunoreactive insulin (IRI), and immunoreactive glucagon (IRG).

Group IV. Nine control patients were studied after $3 \mathrm{~d}$ $(80-86 \mathrm{~h})$ of star ation. We have published the results from studies of five of these patient volunteers requiring diagnostic cardiac catheterization (8). The remaining four patients underwent abdominal surgery, two for repair of stab wounds, one for elective cholecystectomy for uncomplicated cholelithiasis, and one for exploratory laparotomy. During surgery an umbilicoportal cannula was inserted, and patency was maintained with $1,000-2,000 \mathrm{U}$ of heparin in $0.9 \%$ saline per $24 \mathrm{~h}$ (9). This permitted blood sampling from the portal vein after a 3-d fast. The experimental conditions were similar to those for the 3-d fasted cirrhotic patients (see below).

Group V. Two patients free of hepatic parenchymal disease requiring elective abdominal surgery were studied after an overnight (9-14 h) fast, at which time liver biopsies were performed for determination of the activities of gluconeogenic enzymes and hepatic glycogen content under experimental conditions similar to those used for overnight fasted cirrhotic patients (see below).

Patient volunteers in groups III-V had no evidence of heart failure, diabetes mellitus, or other endocrinopathies, nor of hepatic or renal insufficiencies.

\section{Liver biopsies.}

28 liver biopsies were performed on patients with cirrhosis. 5 were needle biopsies and 23 were intraoperative wedge biopsies. In cirrhotic and normal patients, oral nutrients were withheld after 10 p.m., and, when used in cirrhotic patients, supplementary intravenous nutrients were discontinued at midnight on the night before operation. Preoperative medications for all patients were morphine or morphine derivatives with pentobarbital and atropine. General anesthesia was accomplished with nitrous oxide and halothane. Intravenous saline was given until the liver specimens were obtained. Of cirrhotic patients that had open liver biopsies for determination of histology, in only eight were hepatic glycogen contents determined and in only five were gluconeogenic enzymatic activities determined. The liver

${ }^{1}$ Abbreviations used in this paper: AcAc, acetoacetate; $\beta$-OHB, $\beta$-hydroxybutyrate; IRG, immunoreactive glucagon; IRI, immunoreactive insulin; PEP, phosphoenolpyruvate. 
specimens were accordingly divided into three segments: one segment was placed in formaldehyde for determination of histology, another segment was placed in liquid nitrogen for determination of glycogen content, and the third segment was placed in sucrose buffer $(0.25 \mathrm{M}$ sucrose, $10 \mathrm{mM}$ Tris $\mathrm{HCl}, 1$ $\mathrm{mM}$ mercaptoethanol, $\mathrm{pH}$ 7.4) for determination of enzymatic activities.

\section{Catheterization, blood flow, and blood sampling}

Part of the catheterization studies were for the purpose of measuring portal blood pressure and flow rates and performing venous portal angiographic studies to aid in the selection of the type of surgical portosystemic shunt best suited to the individual patient to prevent recurrence of lifethreatening hemorrhage from gastroesophageal varices.

An umbilicoportal cannula was inserted, and patency was maintained initially with $0.9 \%$ saline and subsequently with various intravenous fluids, all containing and delivering $\sim 1,000-2,000 \mathrm{U}$ of heparin per $24 \mathrm{~h}(9)$. Portal and peripheral intravenous glucose, electrolytes, and amino acids were given until the patients were able to orally consume anabolic diets. 4-7 d after hepatic biopsy, the cirrhotic patients were divided into two groups: an overnight $(8-10 \mathrm{~h})$ fasting group I and a 3-d (80-82 h) fasting group II. During the starvation periods $(80-82 \mathrm{~h})$, both cirrhotic patients and normal volunteers with umbilicoportal cannulization received only $0.9 \%$ saline with $1,000-2,000 \mathrm{U}$ of heparin via the umbilicoportal cannula infused at a rate of $\sim 1$ liter $/ 24 \mathrm{~h}$. Supplementary $\mathrm{KCl}$ was given as needed to patients with cirrhosis. Medications were discontinued at least $3 \mathrm{~d}$ before catheterization studies.

After the overnight or the 3-d fast, the patients were taken to the cardiovascular catheterization laboratory and studied in the resting, supine state. A peripheral venipuncture was made for initially giving a prime $(\sim 60 \mathrm{mg})$-continuous $(\sim 12$ $\mathrm{mg} / \mathrm{min}$ ) infusion of sodium $p$-aminohippurate and for subsequently adding a prime $(\sim 2.5 \mathrm{mg})$-continuous $(\sim 0.35 \mathrm{mg} /$ min) infusion solution of indocyanine green dye mixed with 5\% human albumin. A small polyethylene catheter was inserted through the umbilicoportal cannula and rested in a hepatofugal position. Due to technical difficulties, this was accomplished in only 17 cirrhotic patients (Table I). A Cournand catheter (No. 7) (USCI, Billerica, Mass.) was inserted into an exposed superficial antecubital vein and advanced to the main right hepatic vein under fluoroscopic guidance. The catheter tip was placed $\sim 2-3 \mathrm{~cm}$ from the wedge position. The femoral vein was catheterized percutaneously and a Cordis pigtail catheter (No. 8) (Cordis Laboratories Inc., Miami, Fla.) was advanced to the right renal vein. A Cournand needle was inserted percutaneously into a brachial artery. After prime-continuous infusion of dyes was begun and the catheters and needles had been placed, no manipulations were performed for $\sim 30-60 \mathrm{~min}$. At the end of this period, two sets of blood samples were collected simultaneously at 10 min intervals from the brachial artery and the portal and hepatic veins. In addition, from the cirrhotic patients, renal venous blood was collected simultaneously. Isovolumetric quantities of $5 \%$ human albumin in $0.9 \%$ saline and $0.9 \%$ saline were infused through the various catheters in each patient to replace the blood withdrawn during the study. The locations of the catheters were checked immediately before and after each blood sampling period, and, later, the hepatic and renal venous catheter positions were chemically confirmed by negative arteriovenous concentration differences for indocyanine green dye and sodium $p$-aminohippurate, respectively.

Immediately after sampling, aliquots of blood were ana- lyzed for plasma or serum indocyanine green dye concentrations and hematocrits were determined. $10 \mathrm{ml}$ of blood from each sampling site was also immediately injected into $10 \mathrm{ml}$ of ice-cold $1 \mathrm{M}$ perchloric acid and mixed. After centrifugation at $4^{\circ} \mathrm{C}$, portions of the supernatant fluids were rapidly analyzed for pyruvate and AcAc. The remaining supernatant fluids were analyzed for lactate, $\beta-\mathrm{OHB}$, alanine, glutamine, glutamate, and glycerol. Other aliquots of plasma or serum were stored at $-20^{\circ} \mathrm{C}$ until assayed for $p$-aminohippurate, FFA, triglycerides, IRI and IRG. All analyses, except those involving immunoassay, were completed within $3 \mathrm{~d}$ of the catheterization study.

At the conclusion of the blood sampling periods for determining net substrate fluxes and arterial hormone concentrations, the combined indocyanine green dye and $p$-aminohippurate infusion was interrupted. Portal vein blood pressure was determined manometrically, and the flow rates and venous runoff rates were measured by our previously described method in which Lipiodol (E. Fougera and Co., Inc., Hicksville, Long Island, N. Y.) droplet motion within the portal veins was assessed by high-speed cineradiography (10). Cardiac outputs were then determined by dye dilution curves after a single intravenous injection of $5 \mathrm{mg}$ of indocyanine green. Finally, Hypaque (Winthrop Laboratories, Sterling Drug Co., New York) was pressure injected into the umbilicoportal cannulae, and high-speed cineradiography was used to visualize the portal vasculature.

\section{Substrate and hormone determinations}

The analytical methods and the precision for the determination of blood glucose, lactate, pyruvate, glycerol, alanine, glutamine, glutamate, $\beta$-OHB, AcAc, plasma triglyceride and double-extracted plasma FFA, serum IRI, and plasma IRG have been published $(8,11,12)$. Arterial and venous substrate and hormone concentrations were determined simultaneously in duplicate or triplicate.

\section{Calculation of caloric equivalents}

The quantity of hepatic glucose and ketone bodies released into the blood was calculated from the hepatic arteriovenous concentration difference multiplied by the hepatic blood flow rate and corrected to $1.73 \mathrm{~m}^{2}$. The caloric equivalents of these fuels were calculated by the following formula: hepatic caloric equivalents $=$ glucose $\mathrm{mg} / \mathrm{min}-($ lactate + pyruvate $\mathrm{mg}$ per $\mathrm{min} / 2) \times 3.9+($ lactate + pyruvate $\mathrm{mg}$ per $\mathrm{min} / 2) \times 0.21$ + AcAc $\mathrm{mg} / \mathrm{min} \times 4.15+\beta-O H B \mathrm{mg} / \mathrm{min} \times 4.69$.

This formula corrects the caloric equivalents of glucose for recycled lactate and pyruvate and for glycolysis.

\section{Hepatic histology, glycogen content, and enzyme activities}

Liver specimens were fixed in formalin, imbedded in paraffin, cut, and assessed using hemotoxin and eosin, Masson's trichrome, and reticulin stains. The specimens were evaluated by light microscopy for the presence and type of cirrhosis: micronodular, macronodular, mixed, or primary biliary cirrhosis. The degree of the cirrhosis was quantitatively evaluated by the cutout and weigh method. With a light microscope (Carl Zeiss, Inc., New York) with a $\times 10$ ocular and a $\times 1$ objective, color $35-\mathrm{mm}$ photomicrographs were taken of the biopsy specimens stained by Masson's trichrome technique. Usually, five photomicrographs per specimen of adjacent regions were taken. Color $4 \times 6$-inch prints were made from the positive photomicrographs. In the prints the parenchymal liver cells were red-brown and the connective 
tissue blue-green. The borders of all pictures were trimmed and individually weighed and recorded. In the remaining photomicrographs all blank areas were cut out and weighed. Then, all fibrotic regions were cut out and weighed and the remaining parenchymal regions were weighed. As a crosscheck, it was determined that the sum of the weights of blank regions, parenchyma, and fibrotic zones equalled the initial weight of the trimmed photographs. The percentage of fibrotic tissue present was calculated by the formula

$$
\text { Percent fibrosis }=\frac{\text { fibrotic weight }}{\text { total weight }- \text { blank weight }} .
$$

This formula was followed for each photomicrograph and a mean was calculated for each liver specimen.

About $150 \mathrm{mg}$ of duplicate frozen liver specimens were weighed and digested in $30 \% \mathrm{KOH}$ for $30 \mathrm{~min}$ in a boiling waterbath. Glycogen was precipitated with $95 \%$ ethanol, washed twice with $65 \%$ ethanol, and estimated by the anthrone method $(13,14)$.

Liver homogenates $(10 \% \mathrm{wt} / \mathrm{vol})$ were prepared in cold sucrose buffer. In three cirrhotic patients a portion of homogenate was centrifuged at $100,000 \mathrm{~g}$ for $30 \mathrm{~min}$ to obtain the cytosol and the particular fractions for the determination of phosphoenolpyruvate (PEP)-carboxykinase (EC 4.1.1.32) activities in these fractions. To assay mitochondrial enzymes, a portion of liver preparation was treated with Triton X-100 (final concentration, $0.5 \% \mathrm{wt} / \mathrm{vol}$ ) immediately before it was used to determine the activity. Activities of pyruvate carboxylase (EC 6.4.1.1) $(15,16)$ and PEP-carboxykinase $(16,17)$ were assayed by measuring the fixation of $\mathrm{H}^{14} \mathrm{CO}_{3}$. Activities of glucose-6-phosphatase (EC 3.1.3.9) (18) and fructose-1,6diphosphatase (EC 3.1.3.11) (19) were assayed by measuring the release of inorganic phosphate from glucose-6-phosphate and fructose-1,6-diphosphate, respectively. A unit of activity is defined as $1 \mu \mathrm{mol}$ of substrate used or product formed per minute at $37^{\circ} \mathrm{C}$. As a routine, fresh liver from an adult male rat was also processed in an identical fashion to serve as an experimental control for the measurement of hepatic glycogen and enzymes.

\section{Statistical analyses}

Student's $t$ test for small samples was used to compare cirrhotic patient values with normal patient values and to compare overnight fasting and $3-\mathrm{d}$ fasting values. The paired $t$ test was used to compare arteriovenous concentration differences. Linear regressions were calculated by the method of least squares, and their significance was tested by determining the correlation coefficient $(r)$. Values are expressed as the mean \pm SEM $(20)$.

\section{RESULTS}

Blood flow rates (Table I). Cardiac outputs in cirrhotic groups I and II were $6.90 \pm 0.55 \mathrm{liter} / \mathrm{min}$ and $5.47 \pm 0.68 \mathrm{liter} / \mathrm{min}$ in the overnight fasted and 3-d fasted groups, respectively. Calculated total hepatic blood flow rates were $1,877 \pm 362 \mathrm{ml} / \mathrm{min}$ and $1,966 \pm 314$ $\mathrm{ml} / \mathrm{min}$ for the overnight fasted and 3-d fasted cirrhotic groups, respectively. Calculated renal blood flow rates were $1,205 \pm 86 \mathrm{ml} / \mathrm{min}$ and $1,317 \pm 209 \mathrm{ml} / \mathrm{min}$ in the overnight and 3-d fasted cirrhotic groups, respectively. Portal blood flow rates were measured in nine overnight and eight 3-d fasted cirrhotic patients. Seven patients in both group I and group II had hepatopetal blood flow rates that were $673 \pm 136 \mathrm{ml} / \mathrm{min}$ and 496 $\pm 57 \mathrm{ml} / \mathrm{min}$, respectively. In those patients with hepatopetal blood flow, portal blood flow rates ranged widely from 82 to $1,207 \mathrm{ml} / \mathrm{min}$. Two patients in group I and one patient in group II had hepatofugal blood flow. The blood flow rates in these three patients could not be accurately determined (Table I).

Cardiac blood output and hepatic blood flow rates were normal in both group III and group IV (Table I).

Arterial concentrations and arteriovenous concentration differences for overnight fasted patients (Table II). At the time of the catheterization studies steady-state conditions existed.

The arterial blood glucose, lactate, pyruvate, glycerol, glutamine, and glutamate concentrations in overnight fasted cirrhotic patients were indistinguishable from those observed in "normal" overnight fasted patients. However, the mean arterial blood concentration of alanine, the principal gluconeogenic amino acid, was significantly less $(P<0.001)$ in the cirrhotic patients than in the normal patients. The arterial plasma triglyceride concentration was comparable in the overnight fasted cirrhotic and the normal patients. However, the arterial plasma FFA concentration in the overnight fasted cirrhotic patients was elevated about two-fold over the normal value $(P<0.001)$. The arterial blood AcAc and $\beta$-OHB concentrations were increased in the overnight cirrhotic patients by twofold and fourfold, respectively, when compared with the normal overnight fasting values $(P<0.001$ and $P<0.02$, respectively).

The arteriovenous concentration differences show that all overnight fasted cirrhotic patients had a net splanchnic extraction of lactate, pyruvate, glycerol, alanine, and glutamine, and all overnight fasted cirrhotic patients had a net release of glucose and glutamate.

All overnight fasted cirrhotic and normal patients had a net arteriohepatic venous extraction of plasma FFA, and all had a net splanchnic release of AcAc and $\beta-O H B$. The overnight fasted cirrhotic patients and 10 of 13 normal patients also had a net hepatic release of triglycerides.

In an overnight fasted cirrhotic patients, there were no significant arterioportal venous concentration differences for glucose, lactate, pyruvate, glycerol, or glutamate. The extrahepatic splanchnic tissues in these cirrhotic patients extracted glutamine and released alanine. There were no significant arterioportal venous concentration differences for plasma FFA and triglycerides nor for blood AcAc. There was a small but significant extrahepatic splanchnic extraction of arterial blood $\beta$-OHB.

After an overnight fast, the kidneys of cirrhotic patients extracted glutamine and glycerol and released alanine. In addition, the kidneys extracted plasma FFA and blood $\beta$-OHB. There were no significant arterio-

Fuel Homeostasis in Hepatic Cirrhosis 
TABLE I

Catheterization Hemodynamics*

\begin{tabular}{cccccc}
\hline Group & $\begin{array}{c}\text { Cardiac blood } \\
\text { output }\end{array}$ & Cardiac index & $\begin{array}{c}\text { Hepatic blood } \\
\text { flow }\end{array}$ & $\begin{array}{c}\text { Portal blood } \\
\text { flow }\end{array}$ & $\begin{array}{c}\text { Renal blood } \\
\text { flow }\end{array}$ \\
\hline & liter $/ \mathrm{min}$ & liter/min per $\mathrm{m}^{2}$ & $\mathrm{ml} / \mathrm{min}$ & $\mathrm{ml} / \mathrm{min}$ & $\mathrm{ml} / \mathrm{min}$
\end{tabular}

Group I-cirrhotic, $n=16$

$\begin{array}{lrrrcr}1 & 4.73 & 2.82 & 902 & 544 & 1,068 \\ 2 & 10.69 & 4.90 & 6,042 & 82 & 1,692 \\ 3 & 5.66 & 2.87 & 2,043 & - & 1,239 \\ 4 & 8.66 & 4.66 & 3,941 & - & 1,397 \\ 5 & 6.72 & 3.54 & 1,699 & - & 1,487 \\ 7 & 9.53 & 4.65 & 1,264 & - & 1,433 \\ 9 & 4.90 & 2.62 & 1,594 & \text { Hepatofugal } & 1,068 \\ 10 & 10.42 & 5.54 & 1,044 & \text { Hepatofugal } & 1,622 \\ 11 & 5.31 & 3.09 & 1,442 & 624 & 1,340 \\ 12 & 7.23 & 4.79 & - & 513 & 1,556 \\ 13 & 3.84 & 2.60 & 1,439 & 778 & 919 \\ 14 & - & - & 916 & - & 848 \\ 15 & 5.44 & 3.20 & 796 & 965 & 610 \\ 16 & 5.30 & 3.56 & 1,093 & - & 788 \\ 17 & 7.60 & 4.13 & 2,575 & - & - \\ 19 & 7.48 & 4.73 & 1,370 & 1,207 & 1,005 \\ \text { Mean } & 6.90 & 3.80 & 1,877 & 673 & 1,205 \\ \pm \text { SEM } & 0.55 & 0.20 & 362 & 136 & 86 \\ & & & & & \\ \text { Group II- cirrhotic, } n=9 & & & & \\ 20 & 2.40 & 1.38 & 1,262 & 600 & 1,006 \\ 21 & 5.48 & 3.26 & 1,330 & 240 & 2,274 \\ 22 & 8.90 & 4.56 & - & - & - \\ 23 & 5.10 & 2.76 & 3,064 & 728 & - \\ 24 & 3.58 & 2.21 & 3,098 & 462 & 1,874 \\ 25 & 7.28 & 3.73 & - & 522 & 1,350 \\ 26 & 6.77 & 3.66 & 2,224 & \text { Hepatofugal } & 890 \\ 27 & 6.02 & 3.65 & 1,520 & 437 & 934 \\ 28 & 3.69 & 2.13 & 1,264 & 484 & 890 \\ \text { Mean } & 5.47 & 3.04 & 1,966 & 496 & 1,317 \\ \pm \text { SEM } & 0.68 & 0.33 & 314 & 57 & 209\end{array}$

Group III-normal overnight fast, $n=13$

$\begin{array}{cccr}\text { Mean } & 4.12 & 2.15 & 1,377 \\ \pm \text { SEM } & 0.41 & 0.18 & 102\end{array}$

Group IV-normal 3-d fast, $n=9$

$\begin{array}{cccr}\text { Mean } & 6.38 & 3.42 & 1,517 \\ \pm \text { SEM } & 0.91 & 0.40 & 163\end{array}$

* Techniques for determination of cardiac output and regional blood flow are outlined in Methods; 25 of 28 cirrhotic patients studied underwent catheterization studies.

renal venous concentration differences for blood glucose, lactate, pyruvate, glutamate, and AcAc, nor for plasma triglycerides.

Arterial concentrations and arteriovenous concentration differences for 3-d fasted patients (Table II). The arterial blood glucose, lactate, pyruvate, glutamine, and glutamate in the 3-d fasted cirrhotic patients were indistinguishable from those observed in normal 3-d fasted patients. Arterial blood alanine decreased $(P<0.001)$ in the normal patients, but the decrease in alanine concentration was not statistically significant $(P>0.05)$ in the cirrhotic patients. This is consistent with a greater degree of peripheral protein store depletion in cirrhotic patients compared with normal patients at the outset of starvation. Blood glycerol concentration increased in normal patients (8) 
TABLE II

Arterial Concentrations and A-V Differences

\begin{tabular}{|c|c|c|c|c|}
\hline & Artery & $\mathrm{A}-\mathrm{HV}^{*}$ & $\mathbf{A}-\mathbf{P V}^{*}$ & $\mathrm{~A}-\mathrm{RV}^{*}$ \\
\hline \multicolumn{5}{|l|}{ Overnight fasted } \\
\hline \multicolumn{5}{|l|}{ Cirrhotic } \\
\hline Glucose, $m M$ & $5.37 \pm 0.43$ & $-0.32 \pm 0.04 \ddagger$ & $0.00 \pm 0.03$ & $-0.03 \pm 0.02$ \\
\hline Lactate, $\mu M$ & $796 \pm 58$ & $+230 \pm 21 \neq$ & $-4 \pm 21$ & $+22 \pm 15$ \\
\hline Pyruvate, $\mu M$ & $89 \pm 5$ & $+13 \pm 5 \ddagger$ & $-5 \pm 4$ & $+1 \pm 2$ \\
\hline Glycerol, $\mu M$ & $96 \pm 6$ & $+53 \pm 5 \ddagger$ & $+4 \pm 10$ & $+42 \pm 4 \ddagger$ \\
\hline Alanine, $\mu M$ & $214 \pm 12$ & $+63 \pm 6 \ddagger$ & $-29 \pm 8$ & $-23 \pm 4 !$ \\
\hline Glutamine, $\boldsymbol{\mu} M$ & $416 \pm 33$ & $+65 \pm 11 t$ & $+55 \pm 14 \ddagger$ & $+72 \pm 12$ \\
\hline Glutamate, $\mu M$ & $132 \pm 7$ & $-28 \pm 3 \ddagger$ & $0 \pm 2$ & $-6 \pm 4$ \\
\hline FFA, $\mu M$ & $969 \pm 82$ & $+172 \pm 24 \ddagger$ & $+9 \pm 36$ & $+51 \pm 17 \ddagger$ \\
\hline Triglycerides, $\mu M$ & $577 \pm 72$ & $-28 \pm 10 \ddagger$ & $-10 \pm 8$ & $-2 \pm 9$ \\
\hline AcAc, $\mu M$ & $140 \pm 29$ & $-88 \pm 16$ & $+6 \pm 4$ & $-2 \pm 2$ \\
\hline$\beta$-ОНB, $\mu M$ & $253 \pm 63$ & $-91 \pm 19 \ddagger$ & $+27 \pm 6 \ddagger$ & $+20 \pm 6 \rrbracket$ \\
\hline Tot. ket. bod., $\mu M$ & $393 \pm 92$ & $-179 \pm 35 \ddagger$ & $+33 \pm 8 \ddagger$ & $+18 \pm 7 \ddagger$ \\
\hline \multicolumn{5}{|l|}{ Normal } \\
\hline Glucose, $m M$ & $4.87 \pm 0.18$ & - & & \\
\hline Lactate, $\mu M$ & $821 \pm 82$ & - & & \\
\hline Pyruvate, $\mu M$ & $102 \pm 9$ & - & & \\
\hline Glycerol, $\mu M$ & $75 \pm 11$ & - & & \\
\hline Alanine, $\mu M$ & $368 \pm 24$ & - & & \\
\hline Glutamine, $\mu M$ & $461 \pm 31$ & - & & \\
\hline Glutamate, $\mu M$ & $143 \pm 11$ & - & & \\
\hline FFA, $\mu M$ & $456 \pm 61$ & $+166 \pm 26 \ddagger$ & & \\
\hline Triglycerides, $\mu M$ & $1,482 \pm 614$ & $-63 \pm 43$ & & \\
\hline AcAc, $\mu M$ & $67 \pm 6$ & $-26 \pm 5 \ddagger$ & & \\
\hline$\beta$-OHB, $\mu M$ & $75 \pm 14$ & $-23 \pm 4 \downarrow$ & & \\
\hline Tot. ket. bod., $\mu M$ & $142 \pm 17$ & $-49 \pm 8 \ddagger$ & & \\
\hline \multicolumn{5}{|l|}{ 3-d fasted } \\
\hline \multicolumn{5}{|l|}{ Cirrhotic } \\
\hline Glucose, $m M$ & $4.36 \pm 0.36$ & $-0.19 \pm 0.07 \ddagger$ & $+0.06 \pm 0.04$ & $0.00 \pm 0.05$ \\
\hline Lactate, $\mu M$ & $659 \pm 39$ & $+246 \pm 34 \ddagger$ & $-24 \pm 14$ & $+\dot{5} 2 \pm 16 \ddagger$ \\
\hline Pyruvate, $\mu M$ & $76 \pm 5$ & $+21 \pm 4 \ddagger$ & $-11 \pm 8$ & $+11 \pm 2 \ddagger$ \\
\hline Glycerol, $\mu M$ & $90 \pm 9$ & $+54 \pm 5 \ddagger$ & $+23 \pm 11$ & $+35 \pm 6 \ddagger$ \\
\hline Alanine, $\mu M$ & $161 \pm 22$ & $+47 \pm 10 \ddagger$ & $-17 \pm 2 \ddagger$ & $-12 \pm 5$ \\
\hline Glutamine, $\mu M$ & $366 \pm 26$ & $+61 \pm 91$ & $+52 \pm 13 \ddagger$ & $+66 \pm 17 \ddagger$ \\
\hline Glutamate, $\mu M$ & $126 \pm 8$ & $-14 \pm 5 \ddagger$ & $+6 \pm 5$ & $-6 \pm 3$ \\
\hline FFA, $\mu M$ & $1,202 \pm 127$ & $+209 \pm 25 \ddagger$ & $0 \pm 31$ & $+3 \pm 46$ \\
\hline Triglycerides, $\boldsymbol{\mu} M$ & $859 \pm 138$ & $-53 \pm 32$ & $+5 \pm 19$ & $-102 \pm 69$ \\
\hline AcAc, $\mu M$ & $589 \pm 107$ & $-178 \pm 35 \ddagger$ & $-7 \pm 16$ & $-8 \pm 10$ \\
\hline$\beta$-OHB, $\mu M$ & $1,334 \pm 255$ & $-154 \pm 21 \ddagger$ & $+24 \pm 18$ & $+48 \pm 15 \ddagger$ \\
\hline Tot. ket. bod., $\mu M$ & $1,923 \pm 351$ & $-332 \pm 48 \ddagger$ & $+17 \pm 20$ & $+41 \pm 18$ \\
\hline \multicolumn{5}{|l|}{ Normal } \\
\hline Glucose, $m M$ & $3.72 \pm 24$ & $-0.33 \pm 0.03 \ddagger$ & $+0.04 \pm 0.03$ & \\
\hline Lactate, $\mu M$ & $556 \pm 36$ & $+245 \pm 24 \ddagger$ & $-36 \pm 22$ & \\
\hline Pyruvate, $\mu M$ & $61 \pm 4$ & $+16 \pm 2 \ddagger$ & $-19 \pm 6 \rrbracket$ & \\
\hline Glycerol, $\mu M$ & $291 \pm 26$ & $+82 \pm 10 \ddagger$ & $+20 \pm 8$ & \\
\hline Alanine, $\mu M$ & $176 \pm 22$ & $+74 \pm 10 \ddagger$ & $-21 \pm 11$ & \\
\hline Glutamine, $\mu M$ & $404 \pm 19$ & $+22 \pm 19$ & $+14 \pm 6$ & \\
\hline Glutamate, $\boldsymbol{\mu} M$ & $132 \pm 8$ & $-14 \pm 10$ & $-1 \pm 2$ & \\
\hline FFA, $\mu M$ & $1,451 \pm 158$ & $+342 \pm 58 t$ & $+238 \pm 94$ & \\
\hline Triglycerides, $\mu M$ & $1,111 \pm 169$ & $-41 \pm 15 !$ & $-55 \pm 45$ & \\
\hline AcAc, $\mu M$ & $813 \pm 140$ & $-263 \pm 29 !$ & $+12 \pm 8$ & \\
\hline$\beta$-ОНB, $\mu M$ & $1,918 \pm 391$ & $-232 \pm 26$ & $+43 \pm 13 \ddagger$ & \\
\hline Tot. ket. bod., $\mu M$ & $2,730 \pm 527$ & $-495 \pm 35 t$ & $+55 \pm 19$ & \\
\hline
\end{tabular}

Abbreviations: Tot. ket. bod., total ketone bodies; A, artery; A-HV, arteriohepatic venous; A-PV, arterioportal venous; A-RV, arteriorenal venous.

* Negative (-) denotes release; positive (+) denotes uptake.

\$ Concentration statistically different (at least $P<0.05$ ) from the arterial concentration. 
undergoing $3 \mathrm{~d}$ of starvation, but it remained unchanged in the 3-d fasted cirrhotic patients.

The arterial plasma triglyceride concentrations remained stable during starvation and were similar in 3-d fasted cirrhotic and normal patients (8). The increased circulating concentrations of FFA, AcAc, and $\beta$-OHB were also comparable in the 3 - $d$ fasted cirrhotic and normal patients. Further, the rise in total blood ketonebody (AcAc plus $\beta$-OHB) concentration induced by $3 \mathrm{~d}$ of starvation was comparable in cirrhotic and normal patients.

All 3-d fasted cirrhotic and normal patients had net arteriohepatic venous extraction of lactate, pyruvate, glycerol, alanine, glutamine (except 3-d normal patients), and FFA, and they had net release of glucose, glutamate (except 3-d normal patients), AcAc, and $\beta$-OHB. The normal 3-d fasted patients also showed a statistically significant net hepatic release of triglycerides.

There were no statistically significant arterioportal venous concentration differences for glucose, lactate, pyruvate (except 3-d normal patients), glycerol, glutamate, FFA, triglycerides, AcAc, and $\beta$-OHB (except 3-d normal patients). 3-d fasted cirrhotic patients had extrahepatic splanchnic tissue release of alanine and extraction of glutamine $(P<0.05)$.

In all nine 3-d fasted cirrhotic patients, the kidneys extracted lactate, pyruvate, glycerol, and glutamine. There was no mean arteriorenal venous glucose or alanine difference. However, special comments with regard to net renal exchange of glucose are needed. Arteriorenal venous concentration differences for glucose varied from an uptake of $204 \mu \mathrm{mol} / \mathrm{liter}$ to a release of $254 \mu \mathrm{mol} / \mathrm{liter}$ of blood. Rather than assuming that these large and diverse differences are all due to technical limitations and/or the minute difference in the quantity of plasma (water) contained in the renal arterial and venous blood, it is more reasonable to conclude that these glucose differences show that normal kidneys in cirrhotic patients handle glucose in a heterogeneous manner.

There was renal extraction of arterial blood $\beta-\mathrm{OHB}$ but no significant arteriorenal venous concentration differences for AcAc. No statistically significant arteriorenal venous concentration difference in plasma triglycerides was demonstrated in eight of nine 3-d fasted cirrhotic patients. However, in all of these patients, the renal vein plasma triglyceride concentration exceeded the corresponding arterial plasma triglyceride concentration. The minimal arteriorenal venous plasma concentration difference was $6 \mu \mathrm{mol} / \mathrm{liter}$ and the maximal difference was $582 \mu \mathrm{mol} / \mathrm{liter}$. Small arteriovenous differences for triglyceride concentrations can be explained by technical errors inherent in measuring plasma triglycerides (8) and/or by the minute difference in water content of plasma in arterial and renal venous blood. However, large arteriovenous concentration differences probably reflect the ability of the kidney to synthesize and release triglycerides into the bloodstream under certain conditions $(21,22)$.

Net gut, hepatic, and renal substrate rates (Table III). Since the blood supply to the normal liver is derived from both the hepatic and the portal veins, the concentrations of substrates in both blood supplies must be measured and the relative ratio of blood flow from both systems must be known to distinguish net hepatic metabolism from net extrahepatic splanchnic tissue metabolism. Portal blood flow was not measured in the normal patients of this study. Portal blood flow was measured in most of the patients with cirrhosis (Table I), but the quantity of portal blood that shunted around or away from their livers was not measured. Further, the amount of portal blood derived from hepatic arterial blood in the three cirrhotic patients with retrograde portal blood flow was unknown. Nevertheless, pertinent observations were made by showing that there were no significant blood arterioportal venous concentration differences for lactate, pyruvate (except in 3-d fasted normals), glycerol, and glucose. Thus, for these precursors and product, the arteriohepatic venous concentration differences combined with total hepatic blood flow closely reflect net hepatic metabolism for these carbohydrates. In contrast, there were usually arterioportal venous concentration differences for alanine and for glutamine (except in 3-d fasted normals). From animal preparations, other investigators have reported that part of the glutamine carbon skeleton extracted by extrahepatic splanchnic tissue (small intestine) is converted into citrulline, proline, citrate, and lactate and that part of the glutamine nitrogen is converted into ammonia, citrulline, alanine, proline, and glycine $(23,24)$. Thus, the extraction of glutamine by extrahepatic splanchnic tissues is nearly offset by the release of other amino acids, principally alanine. Therefore, the net exchange of alanine, glutamine, and other amino acids by extrahepatic splanchnic tissue during postabsorptive states is probably close to zero. The observed arterioportal venous differences for the selected lipids reported in this study were small or nonexistent. Therefore, disregarding the portal blood flow limitations and the arterioportal venous substrate concentration differences does not introduce major errors in the assumption that net splanchnic exchange closely parallels net hepatic exchange. Nevertheless, when appropriate, extrahepatic splanchnic exchange rates were considered.

After a brief overnight fast (8-10 h), net splanchnic (hepatic) glucose release was $533 \pm 91 \mu \mathrm{mol} / \mathrm{min}$ per $1.73 \mathrm{~m}^{2}$ in the cirrhotic patients. Total net hepatic extraction of the gluconeogenic precursors (lactate, pyruvate, glycerol, amino acid equivalents ${ }^{2}[5,8]$ ) was

\footnotetext{
${ }^{2}$ Amino acid equivalents were calculated by assuming that alanine uptake is $\sim 45 \%$ of the total splanchnic gluconeogenic amino acid exchange $(10,14,44)$.
} 
TABLE III

Net Substrate Release and Uptake

\begin{tabular}{|c|c|c|c|}
\hline & Splanchnic & Gut & Renal \\
\hline \multicolumn{4}{|l|}{ Overnight fasted } \\
\hline \multicolumn{4}{|l|}{ Cirrhotic } \\
\hline Glucose* & $-0.53 \pm 0.09$ & $+0.02 \pm 0.07$ & $-0.06 \pm 0.02$ \\
\hline Lactate $\ddagger$ & $+354 \pm 48$ & $-24 \pm 15$ & $+29 \pm 18$ \\
\hline Pyruvate $\$$ & $+12 \pm 17$ & $-6 \pm 3$ & $+1 \pm 15$ \\
\hline Glycerol $\$$ & $+80 \pm 10$ & $+5 \pm 12$ & $+49 \pm 6$ \\
\hline Alanine & $+121 \pm 18$ & $-22 \pm 11$ & $-27 \pm 6$ \\
\hline Glutamine & $+103 \pm 20$ & $+40 \pm 35$ & $+85 \pm 13$ \\
\hline Glutamate $\ddagger$ & $-56 \pm 13$ & $-2 \pm 1$ & $-7 \pm 5$ \\
\hline FFA $\ddagger$ & $+189 \pm 24$ & $+15 \pm 31$ & $+42 \pm 16$ \\
\hline Triglycerides & $-31 \pm 14$ & $0 \pm 8$ & $-4 \pm 7$ \\
\hline AcAc & $-133 \pm 25$ & $+5 \pm 3$ & $-2 \pm 2$ \\
\hline$\beta$-OHB $\ddagger$ & $-147 \pm 31$ & $+21 \pm 10$ & $+21 \pm 7$ \\
\hline \multicolumn{4}{|l|}{ Normal } \\
\hline FFA $\ddagger$ & $+126 \pm 22$ & & \\
\hline Triglycerides $\ddagger$ & $-52 \pm 35$ & & \\
\hline AcAc $\downarrow$ & $-30 \pm 5$ & & \\
\hline$\beta-\mathrm{OHB} \ddagger$ & $-30 \pm 6$ & & \\
\hline \multicolumn{4}{|l|}{ 3-d fasted } \\
\hline \multicolumn{4}{|l|}{ Cirrhotic } \\
\hline Glucose* & $-0.34 \pm 0.08$ & $+0.03 \pm 0.02$ & $+0.04 \pm 0.04$ \\
\hline Lactate & $+440 \pm 52$ & $-11 \pm 4$ & $+53 \pm 15$ \\
\hline Pyruvate $\ddagger$ & $+37 \pm 10$ & $-2 \pm 2$ & $+15 \pm 5$ \\
\hline Glycerol $\$$ & $+105 \pm 20$ & $+11 \pm 8$ & $+48 \pm 7$ \\
\hline Analine & $+81 \pm 16$ & $-7 \pm 2$ & $-17 \pm 3$ \\
\hline Glutamine & $+107 \pm 21$ & $+28 \pm 7$ & $+96 \pm 26$ \\
\hline Glutamate $\ddagger$ & $-23 \pm 6$ & $+3 \pm 3$ & $-6 \pm 2$ \\
\hline FFA $\ddagger$ & $+261 \pm 86$ & $-2 \pm 10$ & $+23 \pm 49$ \\
\hline Triglycerides $\ddagger$ & $-80 \pm 61$ & $-2 \pm 8$ & $-27 \pm 7$ \\
\hline AcAc & $-328 \pm 69$ & $-6 \pm 11$ & $-3 \pm 18$ \\
\hline$\beta-\mathrm{OHB} \ddagger$ & $-246 \pm 20$ & $+19 \pm 4$ & $+74 \pm 32$ \\
\hline \multicolumn{4}{|l|}{ Normal } \\
\hline Glucose* & $-0.48 \pm 0.06$ & & \\
\hline Lactate $\$$ & $+354 \pm 49$ & & \\
\hline Pyruvate & $+21 \pm 3$ & & \\
\hline Glycerolf & $+87 \pm 19$ & & \\
\hline Alanine $\ddagger$ & $+110 \pm 18$ & & \\
\hline Glutamine & $+47 \pm 42$ & & \\
\hline Glutamate $\ddagger$ & $-30 \pm 23$ & & \\
\hline FFA & $+328 \pm 61$ & & \\
\hline Triglycerides & $-34 \pm 13$ & & \\
\hline AcAc $\downarrow$ & $-402 \pm 77$ & & \\
\hline$\beta-\mathrm{OHB} \ddagger$ & $-345 \pm 55$ & & \\
\hline
\end{tabular}

*Values are expressed as $\mathrm{mmol} / \mathrm{min}$ per $1.73 \mathrm{~m}^{2}$; negative $(-)$ denotes release; positive (+) denotes uptake.

$\ddagger$ Values are expressed as $\mu \mathrm{mol} / \mathrm{min}$ per $1.73 \mathrm{~m}^{2}$; negative (-) denotes release; positive (+) denotes uptake.

$715 \pm 115 \mu \mathrm{mol} / \mathrm{min}$ per $1.73 \mathrm{~m}^{2}$. Assuming that under the influence of hyperglucagonemia, characteristic of patients with hepatic cirrhosis (25-27), these gluconeogenic precursors are quantitatively converted to and released as glucose $(28,29)$ then $\sim 358 \pm 58 \mu \mathrm{mol} / \mathrm{min}$ per $1.73 \mathrm{~m}^{2}$, or $\sim 67 \%$ net hepatic glucose release, can be attributed to gluconeogenesis.
The net splanchnic hepatic release of AcAc in the overnight fasted cirrhotic patients was $133 \pm 25 \mu \mathrm{mol} /$ $\min$ per $1.73 \mathrm{~m}^{2}$, and the $\beta$-OHB production rate was $147 \pm 31 \mu \mathrm{mol} / \mathrm{min}$ per $1.73 \mathrm{~m}^{2}$. In our normal overnight fasted patients, the rates were $30 \pm 5 \mu \mathrm{mol} / \mathrm{min}$ per $1.73 \mathrm{~m}^{2}$ and $30 \pm 6 \mu \mathrm{mol} / \mathrm{min}$ per $1.73 \mathrm{~m}^{2}$ for AcAc and $\beta-\mathrm{OHB}$, respectively. Thus, total ketone-body 
production rates were some four- to fivefold greater in overnight fasted cirrhotic patients, compared with overnight fasted normal patients $(P<0.001)$. It can be estimated that after an overnight fast $\sim 37 \%$ of the extracted plasma FFA $\left(189 \pm 24 \mu \mathrm{mol} / \mathrm{min}\right.$ per $\left.1.73 \mathrm{~m}^{2}\right)$ in cirrhotic patients and $\sim 12 \%$ of the extracted plasma FFA $\left(126 \pm 22 \mu \mathrm{mol} / \mathrm{min}\right.$ per $\left.1.73 \mathrm{~m}^{2}\right)$ in normal patients was converted to ketone bodies after an overnight fast. These observations are in accord with the observations that, after an overnight fast, the circulating concentrations of ketone bodies, FFA, and glucagon and the hepatic extraction rate of FFA are greater in cirrhotic patients than in normal patients $(189 \pm 24$ vs. $126 \pm 22$; $P<0.02)$. A small net hepatic release of triglycerides occurred in the cirrhotic patients after an overnight fast.

In the cirrhotic patients after an overnight fast the extrahepatic splanchnic tissues extracted $21 \pm 10 \mu \mathrm{mol} /$ min per $1.73 \mathrm{~m}^{2}$ of $\beta$-OHB. Thus, this small quantity of $\beta$-OHB should be added to the hepatic ketonebody production rate to prevent under-estimation of the hepatic ketone-body production rate. It should be noted, however, that excluding extrahepatic removal of $\beta$-OHB creates an error in the total hepatic ketonebody production rate of $<8 \%$.

In the cirrhotic patients after an overnight fast, the kidney extracted less glycerol, glutamine, and FFA than the liver. Renal removal of $\beta$-OHB was $21 \pm 7 \mu \mathrm{mol} /$ min per $1.73 \mathrm{~m}^{2}$, or $\sim 8 \%$, of the hepatic total ketonebody production rate.

After $3 \mathrm{~d}$ of starvation, net hepatic glucose release was $339 \pm 82 \mu \mathrm{mol} / \mathrm{min}$ per $1.73 \mathrm{~m}^{2}$ and $476 \pm 55 \mu \mathrm{mol} /$ min per $1.73 \mathrm{~m}^{2}$ for cirrhotic and normal patients, respectively.

After a 3-d fast AcAc plus $\beta$-OHB production rates were $574 \pm 89 \mu \mathrm{mol} / \mathrm{min}$ per $1.73 \mathrm{~m}^{2}$ and $747 \pm 132$ $\mu \mathrm{mol} / \mathrm{min}$ per $1.73 \mathrm{~m}^{2}$ in cirrhotic and normal patients, respectively. There was no difference $(P>0.2)$ in total ketone-body production rates between the $3-\mathrm{d}$ fasted cirrhotic and normal patients. Of the hepatic extracted plasma FFA, $55 \%$ of the $261 \pm 86 \mu \mathrm{mol} / \mathrm{min}$ per $1.73 \mathrm{~m}^{2}$ in cirrhotic and $57 \%$ of the $328 \pm 61 \mu \mathrm{mol} / \mathrm{min}$ per 1.73 $\mathrm{m}^{2}$ in normal patients could have been converted to ketone bodies after the 3-d fast. In addition, 3-d fasted normal patients showed a net hepatic release of triglycerides.

In the cirrhotic patients subjected to a 3-d fast, only glutamine was extracted by extrahepatic splanchnic tissues from blood, at a rate of $28 \pm 7 \mu \mathrm{mol} / \mathrm{min}$ per 1.73 $\mathrm{m}^{2}$, and alanine was released at a rate of $7 \pm 2 \mu \mathrm{mol} /$ min per $1.73 \mathrm{~m}^{2}$.

The kidneys extracted $53 \pm 15 \mu \mathrm{mol}$ of lactate, $15 \pm 5$ $\mu \mathrm{mol}$ of pyruvate, $48 \pm 7 \mu \mathrm{mol}$ of glycerol. $96 \pm 26$ $\mu \mathrm{mol}$ of glutamine, and $74 \pm 32 \mu \mathrm{mol}$ of $\beta-\mathrm{OHB} / \mathrm{min}$ per $1.73 \mathrm{~m}^{2}$, but there was no significant net exchange of alanine, glutamate, FFA, or AcAc. Renal extraction of glucose equivalents (lactate + pyruvate + glycerol $+\alpha$-ketoglutarate equivalents/2 [11]) was $103 \pm 19$ $\mu \mathrm{mol} / \mathrm{min}$ per $1.73 \mathrm{~m}^{2}$ compared to hepatic extraction of $374 \pm 36 \mu \mathrm{mol} / \mathrm{min}$ per $1.73 \mathrm{~m}^{2}$. Nevertheless, mean renal glucose production was nil rather than being approximately one-third of the hepatic production rate. There was, however, a net release of triglycerides into renal venous plasma of $27 \pm 7 \mu \mathrm{mol} / \mathrm{min}$ per 1.73 $\mathrm{m}^{2}(P<0.02)$.

There was no correlation between renal glucose exchange and hepatic glucose release $(r=-0.18$; $P>0.5)$, renal plasma FFA uptake $(r=-0.20 ; P>0.3)$ or arterial plasma glucagon concentration $(r=-0.02$; $P>0.9$ ) in overnight fasted and 3-d fasted cirrhotic patients.

Hepatic histology, glycogen content, and enzyme activity. Light microscopy revealed the presence of micronodular cirrhosis in 21 of 28 liver specimens. Two patients had mixed micronodular and macronodular cirrhosis, four patients had macronodular cirrhosis, and one patient had biliary cirrhosis. The etiology of the cirrhosis was alcohol related in all 21 patients with micronodular cirrhosis, in two patients with macronodular cirrhosis, and in two patients with mixed cirrhosis. The etiologies in two other patients with macronodular cirrhosis were chronic active hepatitis and $\alpha$-1-antitrypsin deficiency. 10 of 25 patients with alcohol-related cirrhosis had evidence of fatty changes, which is probably indicative of relatively recent alcohol-induced injury before biopsy; 15 cirrhotic patients had no fatty changes, probably due to their long hospitalization with alcohol abstinence before biopsy. Nevertheless, 7 of these 15 patients had residual alcoholic hepatitis characterized by the presence of injured cells with Mallory's hyaline bodies. The cutout and weigh method revealed that scar tissue composed $41 \pm 3 \%$ of the hepatic parenchymal tissue.

The glycogen content in the eight cirrhotic patients was $2.58 \pm 0.36 \mathrm{mg} / 100 \mathrm{mg}$ liver, which appeared to be lower than that observed (3.20-4.80 mg/100 mg liver) in the two normal patients and also lower than the mean glycogen content of $4.37 \mathrm{mg} / 100 \mathrm{mg}$ liver reported by others (30) in livers of 58 healthy volunteers after a 12-16-h overnight fast.

The activities of four key gluconeogenic enzymes, namely, PEP-carboxykinase, pyruvate carboxylase, fructose-1,6-diphosphatase, and glucose-6-phosphatase, were measured in liver specimens from five cirrhotic patients and two normal patients. In three cirrhotic patients in whom the subcellular distribution of PEP-carboxykinase in the liver was measured, the distribution of this enzyme between the mitochondrial and cytosolic compartments ranged from 40 to $60 \%$ of the total activity. This is consistent with the previously reported distribution of this enzyme in human liver (31). Three of five cirrhotic patients had hepatic PEP-carboxykinase levels within the normal range (14-25 U/g liver). Our two normal values (17-25 U/g 
liver) agree with previously reported values in adults (32). The other two cirrhotic patients had lower values (4.0-7.1 U/g liver). The pyruvate carboxylase activity in five cirrhotic livers was $2.6 \pm 0.6 \mathrm{U} / \mathrm{g}$ liver. Although we did not measure this enzyme in the two control subjects, the previously reported values for the control subjects (aged $8 \mathrm{yr}$ to adult) ranged from 2 to $12 \mathrm{U} / \mathrm{g}$ liver $(32,33)$. The fructose-1,6-diphosphatase activity in the five cirrhotic $(1.3 \pm 0.2 \mathrm{U} / \mathrm{g}$ liver $)$ and the two normal livers (1.0-2.1 U/g liver) were similar. However, the activities of glucose-6-phosphatase in the five cirrhotic livers $(4.1 \pm 0.5 \mathrm{U} / \mathrm{g}$ liver $)$ were lower than that observed in the two normal livers $(6.9-11.5 \mathrm{U} / \mathrm{g}$ liver).

Insulin and glucagon arterial concentration (Table IV). After an overnight fast, patients with cirrhosis has serum IRI concentrations that were twofold greater and plasma IRG concentrations that were fivefold greater than those observed in normal patients. These results were in agreement with the results reported by others (25-27). The expected decreases in serum IRI concentrations occurred after the 3-d fasts in both cirrhotic and normal patients.

\section{DISCUSSION}

To delineate the importance of extrahepatic exchange rates on total splanchnic exchange rates during various states of nutrient deprivation, the exchange rates of carbohydrates, lipids, and amino acids across the gut were measured. The lack of a large extraction or release rate of any measured substrate suggests that the energy requirements for extrahepatic splanchnic tissue in the resting postabsorptive or starving states were either small or supplied by endogenous sources. Thus, extrahepatic splanchnic tissue did not appear to have major quantitative influences on hepatic exchange rates.

Although it is known that the liver contributes fuels to the bloodstream via glycogenolysis, gluconeogene-

TABLE IV

Hormonal Arterial Concentrations

\begin{tabular}{|c|c|}
\hline Overnight fasted & \\
\hline Cirrhotic & \\
\hline Insulin, $\mu U / m l$ & $61 \pm 26^{*}$ \\
\hline Glucagon, $p g / m l$ & $1,021 \pm 468$ \\
\hline Normal & \\
\hline Insulin, $\mu U / m l$ & $27 \pm 4 \ddagger$ \\
\hline Glucagon, $p g / m l$ & $188 \pm 46$ \\
\hline 3-d fasted & \\
\hline Cirrhotic & \\
\hline Insulin, $\mu U / m l$ & $18 \pm 3^{*}$ \\
\hline Normal & \\
\hline Insulin, $\mu U / m l$ & $12 \pm 3 \ddagger$ \\
\hline
\end{tabular}

Differences were statistically significant $(P<0.05)$ between overnight fasted cirrhotic patients and 3-d fasted cirrhotic patients $\left({ }^{*}\right)$ and between overnight fasted normal and 3-d fasted normal patients $(\sharp)$. sis, and ketogenesis, exactly how these processes are quantitatively related has not been clearly defined. Fig. 1 shows net splanchnic (hepatic) glucose and ketone-body exchange rates for normal and cirrhotic patients after an overnight and after a 3-d fast. Wahren et al. (5) reported that the net splanchnic glucose production in 24 normal volunteers after a 12- to 14 -h overnight fast was $856 \pm 99 \mu \mathrm{mol} / \mathrm{min}$ per $1.73 \mathrm{~m}^{2}$. Approximately $80 \%$ of this glucose release was attributed to hepatic glycogenolysis, and the remaining $20 \%$, or $182 \mu \mathrm{mol} / \mathrm{min}$ per $1.73 \mathrm{~m}^{2}$, was attributed to gluconeogenesis from lactate, pyruvate, glycerol, and amino acids. Our results show that after an overnight fast the net splanchnic glucose production rate in cirrhotic patients was $533 \pm 91 \mu \mathrm{mol} / \mathrm{min}$ per $1.73 \mathrm{~m}^{2}$. Although the duration of the fast in our cirrhotic patients was slightly shorter than that of the normal volunteers of Wahren et al. (5), our patients with severe cirrhosis had a mean hepatic glucose release rate of only $62 \%$ of that observed by Wahren et al. in normal subjects. In contrast to reduced net hepatic glucose production rates in cirrhotic patients, the total extraction rate $\left(715 \pm 115 \mu \mathrm{mol} / \mathrm{min}\right.$ per $\left.1.73 \mathrm{~m}^{2}\right)$ of gluconeogenic precursors (lactate, pyruvate, glycerol, and estimated $\alpha$-amino acid equivalents) by the cirrhotic livers was greater than that reported for normal subjects (5). In the presence of hyperglucagonemia it is likely that these precursors were quantitatively converted to and released as glucose and could account for $358 \mu \mathrm{mol} / \mathrm{min}$ per $1.73 \mathrm{~m}^{2}$, or $67 \%$, of the hepatic glucose production rate in the cirrhotic patients after an overnight fast. Thus, the total extraction rate for the gluconeogenic precursors in cirrhotic patients was about twofold greater than that reported by Wahren et al. (5) for normal subjects. It should be noted, however, that not all of the alanine and the other gluconeogenic amino acids removed by the normal liver after an overnight fast were quantitatively converted to glucose $(28,34)$. Therefore, the actual difference in gluconeogenesis between overnight fasted cirrhotic patients and normal volunteers was probably greater than the extraction rates of the total gluconeogenic precursors suggest.

Hepatic gluconeogenesis from alanine has been reported to be impaired immediately after the consumption of ethanol $(35,36)$. However, in our patients in whom alcohol abstinence was observed for days to months during hospitalization, hepatic extraction of alanine and presumed gluconeogenesis from alanine was greater than previously reported after an overnight $(5,34)$ and $3-\mathrm{d}(8)$ fasts or during moderate to severe diabetic ketoacidosis (11). This heightened gluconeogenesis from alanine and presumably from other amino acids derived primarily from accelerated protein degradation after an overnight fast may be partly responsible for the marked peripheral muscle wasting known in patients with alcoholic cirrhosis. 


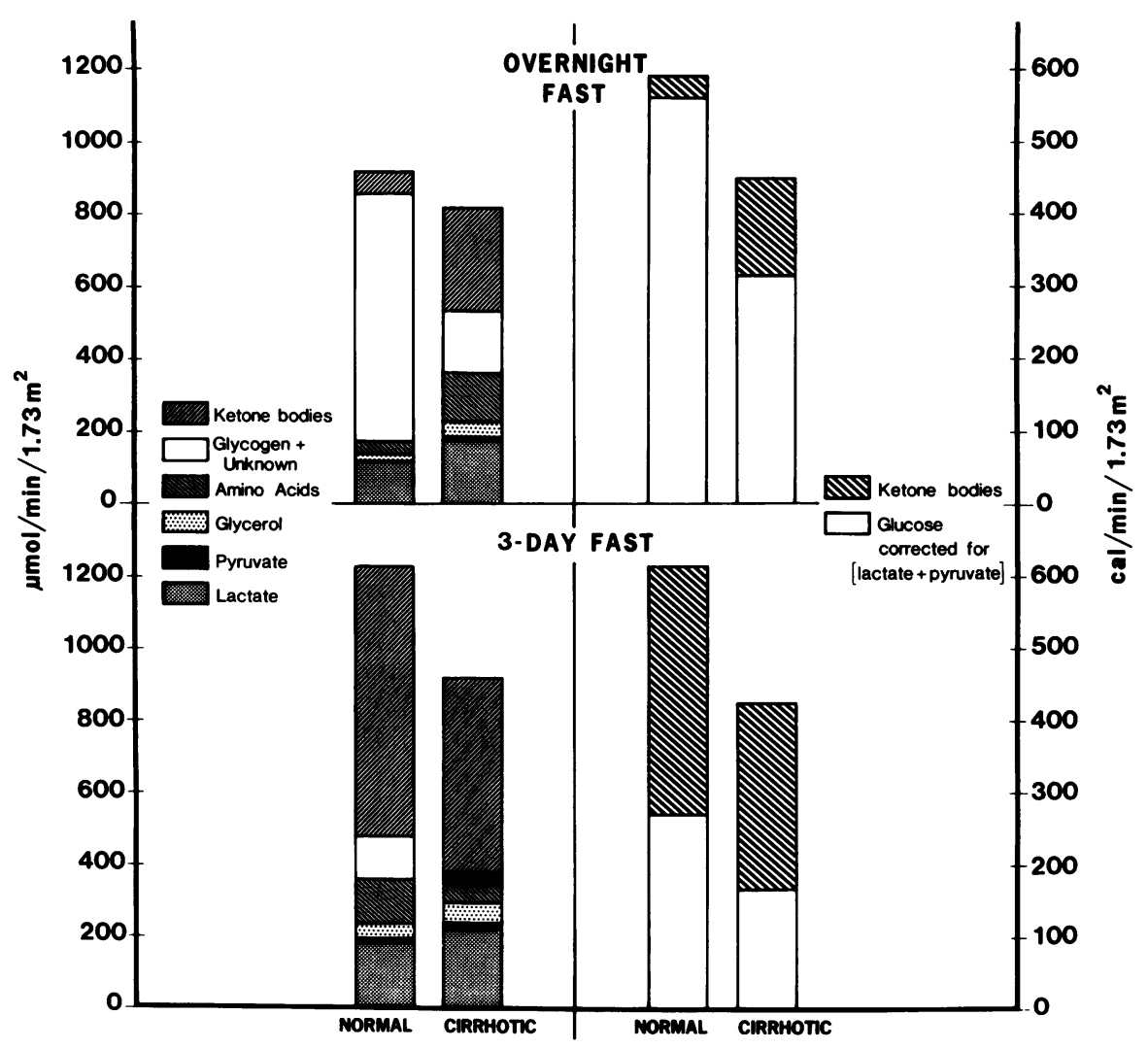

FIGURE 1 Relationships among hepatic glycogenolysis, gluconeogenesis, and ketogenesis (left) and relationship between caloric equivalents derived from glucose and ketone bodies (right) after overnight (upper part) and 3-d (lower part) fasts in normal and cirrhotic patients.

In contrast to diminished hepatic glucose production in cirrhotic patients after an overnight fast, the hepatic production rate of AcAc plus $\beta$-OHB was augmented four- to fivefold in cirrhotic patients and amounted to $280 \pm 55 \mu \mathrm{mol} / \mathrm{min}$ per $1.73 \mathrm{~m}^{2}$ (compared with $60 \pm 8 \mu \mathrm{mol} / \mathrm{min}$ per $1.73 \mathrm{~m}^{2}$ in normal patients; Fig. 1).

After a 3-d fast, hepatic glucose production decreased to $339 \pm 82 \mu \mathrm{mol} / \mathrm{min}$ per $1.73 \mathrm{~m}^{2}$ in our cirrhotic patients. All of this glucose could be accounted for by gluconeogenesis. In our normal patients hepatic glucose production was $476 \pm 55 \mu \mathrm{mol} / \mathrm{min}$ per $1.73 \mathrm{~m}^{2}$, $72 \%$ of which could be attributed to gluconeogenesis. Hepatic AcAc plus $\beta-\mathrm{OHB}$ production increased to $574 \pm 89 \mu \mathrm{mol} / \mathrm{min}$ per $1.73 \mathrm{~m}^{2}$ in cirrhotic patients and to $747 \pm 132 \mu \mathrm{mol} / \mathrm{min}$ per $1.73 \mathrm{~m}^{2}$ in normal patients after the 3-d fast.

Fig. 1 (left side) shows the quantitative and reciprocal relationship between the percentage of glucose released, either by glycogenolysis or gluconeogenesis after overnight and 3-d fasts. Although gluconeogenesis was increased after the 3-d fasts, the quantity of glucose supplied by the liver after a 3-d fast from gluconeogenesis was always far less than the quantity transiently supplied by glycogenolysis after the overnight fast. However, this deficit in hepatic glucose release after $3 \mathrm{~d}$ of fasting was offset by the ability of the liver to increase the release of AcAc and $\beta-O H B$ to the bloodstream, thereby diminishing glucose utilization by peripheral tissues and, thus, maintaining glucose homeostasis. The reciprocal relationship between total hepatic glucose release and total hepatic ketone-body release is also shown in Fig. 1. After an overnight fast, when glucose release was high, ketonebody release was low. Conversely, after a 3-d fast when glucose release was low, ketone-body release was high. These divergent hepatic production rates of glucose and ketone bodies between the overnight and 3-d fasts were less obvious in cirrhotic patients. Diminished hepatic glucose production rates after the overnight fast in cirrhotic patients was accompanied by increased hepatic ketone-body production rates. Thus, after an overnight fast the livers of cirrhotic patients exhibited a metabolic profile that reflected a more advanced state of starvation. Therefore, the differences between hepatic production rates of glucose and ketone bodies in cirrhotic patients after an overnight and a 3-d fast were less pronounced than those observed in normal patients.

Although the types of fuel released by the liver are different, the caloric equivalents of these fuels (Fig. 1 , right side), corrected for recycled lactate and 
pyruvate, added to the bloodstream by the livers after an overnight and a 3-d fast are comparable, amounting to $\sim 588 \mathrm{cal} / \mathrm{min}$ per $1.73 \mathrm{~m}^{2}$ and $610 \mathrm{cal} / \mathrm{min}$ per 1.73 $\mathrm{m}^{2}$, respectively, for normal hepatic contributions and amounting to $\sim 442 \mathrm{cal} / \mathrm{min}$ per $1.73 \mathrm{~m}^{2}$ and $422 \mathrm{cal} /$ min per $1.73 \mathrm{~m}^{2}$, respectively, for cirrhotic liver contributions. Expressing the results as caloric equivalents clearly illustrates that the relevance of glucose or ketone bodies produced by the liver in maintaining fuel homeostasis is greater when one fuel is integrated with the production rate of the other. The results also show that after an overnight or a 3-d fast the cirrhotic liver delivers fewer caloric equivalents to the bloodstream than the normal liver delivers.

We were surprised to find that gluconeogenesis was augmented in cirrhotic patients whose liver biopsies showed severely deranged and fibrotic tissues. This was unsuspected because it had previously been suggested that gluconeogenesis may be diminished in patients with liver disease as a consequence of malfunctioning gluconeogenic enzymes (37). Therefore, additional liver tissue was obtained from some patients with cirrhosis to measure the activities of glucose-6phosphatase, fructose-1,6-diphosphatase, pyruvate carboxylase, and PEP-carboxykinase. The activities of these key gluconeogenic enzymes were similar to those observed in the normal controls, despite the fact that $15-39 \%$ of the liver in the cirrhotic patients from whom the liver biopsies were obtained consisted of scar tissue. In addition, these liver specimens had light microscope evidence of inflammatory activity and alcoholic hepatitis resulting in further loss of hepatocytes. Although it is recognized that these enzyme activities were measured in vitro under optimal conditions, they appeared to have more than sufficient (and in most cases manyfold excess) activity per gram of tissue to support the rate of hepatic gluconeogenesis observed in vivo.

Since most patients with alcoholic cirrhosis have liver masses that exceed the normal liver weight, impaired gluconeogenesis due to lack of enzymatic activity is probably rare in cirrhosis. This conclusion is supported by the catheterization results from one patient, whose liver biopsy revealed that $79 \%$ of the hepatic parenchyma was composed of scar tissue. Her net hepatic glucose production rate after an overnight fast was $208 \mu \mathrm{mol} / \mathrm{min}$ per $1.73 \mathrm{~m}^{2}$, and her total extraction rate of lactate, pyruvate, glycerol, alanine, and amino acid equivalents was $186 \mu \mathrm{mol} / \mathrm{min}$ per 1.73 $\mathrm{m}^{2}$, which could account for $89 \%$ of her net hepatic glucose production rate. Thus, the results from her balance studies suggest that she had sufficient enzymatic activity to support normal rates of gluconeogenesis but lacked normal rates of glycogenolysis. Nevertheless, patients with sufficient gluconeogenic capacity in the basal resting state may not have adequate enzymatic activity to maintain gluconeogenesis under stressful conditions such as exercise, trauma, or sepsis.
In the cirrhotic patients after an overnight fast glycogenolysis accounted for $\sim 229 \mu \mathrm{mol} / \mathrm{min}$ per $1.73 \mathrm{~m}^{2}$ of the hepatic glucose released; in the normal subjects reported by others, glycogenolysis accounted for $\sim 724$ $\mu \mathrm{mol} / \mathrm{min}$ per $1.73 \mathrm{~m}^{2}$ of the hepatic glucose released (5). A greater glucose release rate from hepatic glycogenolysis in normal subjects after an overnight fast than in cirrhotic patients after a similar fast is in accordance with a greater liver glycogen content in normal people $(4-5 \% / w t)(30)$ than in cirrhotic patients $(1-3 \% / w t)$. It is likely that cirrhotic livers with grossly deranged architecture and extensive fibrosis probably do not have enough space in residual or regenerated hepatocytes to store normal quantities of glycogen. Spacial limitations for glycogen storage may be partly, if not primarily, the cause for hepatic insensitivity to insulin in cirrhosis.

On the basis of previous observations that showed that the kidney could contribute glucose to the bloodstream after 5-6 wk of starvation (38), at the onset of these studies we believed that renal gluconeogenesis may have a role in maintaining glucose homeostasis and thus fuel homeostasis in cirrhotic patients. However, there were no differences in the mean arteriorenal venous glucose concentrations after the overnight or 3-d fasts.

Both in vitro (21) and in vivo (22) studies have shown that kidney tissue can synthesize triglycerides from palmitic acid and ketone bodies. Other studies have shown that the kidneys remove more substrates from the bloodstream than necessary to support renal fuel requirements (39). Therefore, it is possible that under the proper conditions the kidneys could remove lipid precursors from the bloodstream and contribute lipoproteins to the bloodstream. After the 3-d fast our cirrhotic patients added triglyceride to renal venous plasma at a rate of $27 \pm 7 \mu \mathrm{mol} / \mathrm{min}$ per $1.73 \mathrm{~m}^{2}$. If this observation is valid it appears that under certain conditions the kidneys may have a role in making a net contribution of triglycerides to the bloodstream. That this is likely receives support from the recent observation that avian kidney synthesizes apoprotein B, suggesting that kidney may be a source of plasma lipoprotein (40). Our observation that kidneys release triglycerides into plasma after $3 \mathrm{~d}$ of starvation needs to be verified and extended to define the importance of the kidneys as a source of various plasma lipoproteins.

\section{ACKNOWLEDGMENTS}

We wish to thank the nursing staff of the General Clinical Research Center for their assistance. We also would like to thank Wilkie Buick for its support.

This work was supported in part by grants from the U. S. Public Health Service, AM25386, AM27713, AM19397, HD12643, and RR349, General Clinical Research Centers Branch, National Institutes of Health.

\section{REFERENCES}

1. U. S. Department of Health, Education, and Welfare. 1974. Second Special Report to the U. S. Congress on Alcohol 
and Health. Department of Health, Education and Welfare publication 017-024000399.

2. Lieber, C. S. 1978. Pathogenesis and early diagnosis of alcoholic liver injury. N. Engl. J. Med. 298: 888-893.

3. Myers, J. D. 1950. Net splanchnic glucose production in normal man and in various disease states. J. Clin. Invest. 29: $1421-1429$.

4. Reichle, F. A., O. E. Owen, M. Golsorkhi, and T. Kreulen. 1978. Hepatic metabolism in patients with alcoholic cirrhosis. Surgery (St. Louis). 84: 33-36.

5. Wahren, J., P. Felig, E. Cerasi, and R. Luft. 1972. Splanchnic and peripheral glucose and amino acid metabolism in diabetes mellitus. J. Clin. Invest. 51: $1870-1878$

6. Patek, A. J., I. G. Toth, M. G. Saunders, G. A. M. Castro, and J. J. Engel. 1975. Alcohol and dietary factors in cirrhosis. Arch. Intern. Med. 135: 1053-1057.

7. Brannon, E. S., A. J. Merrill, J. V. Warren, and E. A. Stead, Jr. 1945. The cardiac output in patients with chronic anemia as measured by the technique of right atrial catheterization. J. Clin. Invest. 24: 332-336.

8. Garber, A. J., P. H. Menzel, G. Boden, and O. E. Owen. 1974. Hepatic ketogenesis and gluconeogenesis in humans. J. Clin. Invest. 54: 981-989.

9. Reichle, F. A., M. P. Brigham, R. R. Tyson, R. L. Soulen, A. M. Samii, and G. P. Rosemond. 1971. Clinical application of operative umbilical vein cannulation. Surg. Gynecol. Obstet. 133: 39-43.

10. Reichle, F. A., M. Sovak, R. L. Soulen, and G. P. Rosemond. 1972. Portal blood flow determination in the unanesthetized human by umbilicoportal cannulation. J. Surg. Res. 12: 146-150.

11. Owen, O. E., B. S. B. Block, M. Patel, G. Boden, M. McDonough, T. Kreulen, C. R. Shuman, and G. A. Reichard, Jr. 1977. Human splanchnic metabolism during diabetic ketoacidosis. Metab. Clin. Exp. 26: 381-398.

12. Owen, O. E., M. A. Mozzoli, G. Boden, M. S. Patel, G. A. Reichard, Jr., V. Trapp, C. R. Shuman, and P. Felig. 1980. Substrate, hormone and temperature responses in males and females to a common breakfast. Metabolism Clin. Exp. 29: 511-523.

13. Van Handel, E. 1965. Estimation of glycogen in small amounts of tissue. Anal. Biochem. 11: 256-265

14. Seifter, S., S. Dayton, B. Novic, and E. Muntwyler. 1950. The estimation of glycogen with the anthrone reagent. Arch. Biochem. Biophys. 25: 191-200.

15. Utter, M. F., and D. B. Keech. 1963. Pyruvate carboxylase. I. Nature of the reaction. J. Biol. Chem. 238: 2603-2608.

16. Ballard, F. J., and R. W. Hanson. Phosphoenolpyruvate carboxykinase and pyruvate carboxylase in developing rat brain. Biochem. J. 104: 866-871.

17. Chang, H-C., and M. D. Lane. 1966. The enzymatic carboxylation of phosphoenolpyruvate. II. Purification and properties of liver mitochondrial phosphoenolpyruvate carboxylase. J. Biol. Chem. 241: 2413-2420.

18. Swanson, M. A. 1955. Glucose-6-phosphatase from liver. Methods Enzymol. 2: 541-543.

19. McGilvery, R. W. 1955. Fructose-1,6-diphosphatase from liver. Methods Enzymol. 2: 543-546.

20. Snedecor, G. W., and W. G. Cochran. 1967. Statistical Methods. Iowa State University Press, Ames.

21. Weidemann, M. J., and H. A. Krebs. 1969. The fuel of respiration of rat kidney cortex. Biochem.J. 112: 149-166.

22. Barac-Nieto, M., and J. J. Cohen. 1971. The metabolic fates of palmitate in the dog kidney in vivo. Evidence for incomplete oxidation. Nephron. 8: 488-499.

23. Windmueller, H. G., and A. E. Spaeth. 1974. Uptake and metabolism of plasma glutamine by the small intestine. J. Biol. Chem. 249: 5070-5079.

24. Windmueller, H. G., and A. E. Spaeth. 1978. Identification of ketone bodies and glutamine as the major respiratory fuels in vivo for postabsorptive rat small intestine.J. Biol. Chem. 253: 69-76.

25. Marco, J., J. Diego, M. L. Villanueva, M. Diaz-Fierros, I. Valverde, and J. M. Segovia. 1973. Elevated plasma glucagon levels in cirrhosis of the liver. N. Engl. J. Med. 289: $1107-1111$

26. Walker, C., W. Peterson, Jr., and R. Unger. 1974. Blood ammonia levels in advanced cirrhosis during therapeutic elevation of the insulin:glucagon ratio. N. Engl. J. Med. 291: 168-171.

27. Sherwin, R., J. Prakash, R. Hendler, P. Felig, and H. O. Conn. 1974. Hyperglucagonemia in Laennec's cirrhosis. The role of portal-systemic shunting. N. Engl. J. Med. 290: 239-242.

28. Chiasson, J. L., J. E. Liljenquist, B. C. Sinclair-Smith, and W. W. Lacy. 1975. Gluconeogenesis from alanine in normal postabsorptive man. Intrahepatic stimulatory effect of glucagon. Diabetes. 24: 574-584.

29. Huibregtse, C. A., G. A. Rufo, and P. D. Ray. 1977. Gluconeogenesis in rabbit liver. II. Gluconeogenesis and its enhancement by glucagon, epinephrine and cyclic AMP. Biochim. Biophys. Acta. 499: 99-110.

30. Nilsson, L. H. 1973. Liver glycogen content in man in the postabsorptive state. Scand. J. Clin. Lab. Invest. 32: $317-323$.

31. Hanson, R. W., and A. J. Garber. 1972. Phosphoenolpyruvate carboxykinase. I. Its role in gluconeogenesis. Am. J. Clin. Nutr. 25: 1010-1021.

32. Atkin, B. M., N. R. M. Buist, M. F. Utter, A. B. Leiter, and B. Q. Banker. 1979. Pyruvate carboxylase deficiency and lactic acidosis in a retarded child without Leigh's disease. Pediatr. Res. 13: 109-116.

33. Grover, W. D., V. H. Auerbach, and M. S. Patel. 1972. Biochemical studies and therapy in subacute necrotizing encephalomyelopathy (Leigh's syndrome). J. Pediatr. 81: $39-44$.

34. Chiasson, J. L., R. L. Atkinson, A. D. Cherrington, U. Keller, B. C. Sinclair-Smith, W. Lacy, and J. E. Liljenquist. 1979. Effects of fasting on gluconeogenesis from alanine in nondiabetic man. Diabetes. 28: 56-60.

35. Kreisberg, R. A., A. M. Siegal, and W. C. Owen. 1972. Alanine and gluconeogenesis in man: effect of ethanol. J. Clin. Endocrinol. Metab. 34: 876-883.

36. Arky, R. A. 1971. The effect of alcohol on carbohydrate metabolism: carbohydrate metabolism in alcoholics. In The Biology of Alcoholism. B. Kissin and H. Begleiter, editors. Plenum Press, New York. 1: 197-227.

37. Newsholme, E. A. 1976. Role of the liver in integration of fat and carbohydrate metabolism and clinical implications in patients with liver disease. In Progress in Liver Diseases. Vol. V. H. Popper and F. Schaffner, editors. Grune \& Stratton, Inc., New York. 125-135.

38. Owen, O. E., P. Felig, A. P. Morgan, J. Wahren, and G. F. Cahill, Jr. 1969. Liver and kidney metabolism during prolonged starvation. J. Clin. Invest. 48: 574-583.

39. Cohen, J. J., and M. Barac-Nieto. 1973. Renal metabolism of substrates in relation to renal function. In Handbook of Physiology. J. Orloff, R. W. Berliner, and S. R. Geiger, editors. American Physiological Society, Washington, D. C. 909-1001.

40. Blue, M-L., A. A. Protter, and D. L. Williams. 1980. Biosynthesis of apolipoprotein B in rooster kidney, intestine, and liver. J. Biol. Chem. 255: 10048-10051. 